\title{
EVALUATION OF THE CHROMATIC INDUCTION INTENSITY ON MUNKER-WHITE SAMPLES
}

\author{
MiLKOVIC, M.; MrVAC, N. \& BolanCA, S.
}

Abstract: Systems of parallel lines which are similar or even equal to MunkerWhite's samples in their shape are used in different designer's solutions. Many of these solutions become the samples which have to be reproduced in some defined cases with great degree of exactness.

However, because of the manifestation of the determined psychophysical effects the usage of such line systems can cause potential aberration in the perception of the desired colour of particular elements of the reproduced samples.

The changes in colour perception on Munker-White's samples appear as the consequence of the geometrical structure in combination with the psychophysical visual effects of chromatic induction and assimilation.

In this sense the experimental investigations are directed so that they enable the determination of the influence of particular standard rendering methods on the magnitude of the most intensive effect which is manifested on different types of Munker-White's sample, i.e. the effect of chromatic induction.

Key words: Munker-White's effect, chromatic inductions, ICC rendering mehtod
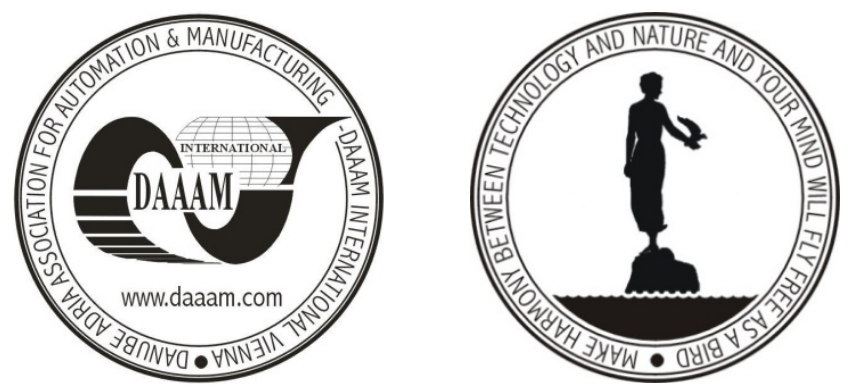

Authors' data: Dr. Milkovic, M[arin]*; Prof. Mrvac, N[ikola]**; Dr. Bolanca, S[tanislav] ${ }^{* * *}$, ${ }^{*}$ Graficki zavod hrvatske, M.Resetara 44, 10000, Zagreb, HR, **Faculty of Graphic Arts, Desno Sredicko 2a, 47206 Lasinja, HR,*** Faculty of Graphic Arts, Getaldiceva 2, 10000, Zagreb, HR, marin.milkovic@gzh.hr, mrvac@grf.hr, stanislav.bolanca@grf.hr

This Publication has to be referred as: Milkovic, M[arin]; Mrvac, N[ikola] \& Bolanca, S[tanislav] (2008). Evaluation of the Chromatic Induction Intensity on Munker-White Samples, Chapter 41 in DAAAM International Scientific Book 2008, pp. 485-498, B. Katalinic (Ed.), Published by DAAAM International, ISBN 978-3901509-66-7, ISSN 1726-9687, Vienna, Austria

DOI: $10.2507 /$ daaam.scibook.2008.41 